Central European Journal of Energetic Materials, 2016, 13(1), 183-197

ISSN 1733-7178

e-ISSN 2353-1843

\title{
Statistics of Fragment Dispersion by Explosion in a Fragment Generator Warhead
}

\author{
Kusumkant D. DHOTE ${ }^{1 *}$, Krothapalli P. S. MURTHY ${ }^{1}$, \\ Kizhakkel M. RAJAN ${ }^{1}$, Mahesh M. SUCHEENDRAN ${ }^{2}$ \\ ${ }^{1}$ Armament Research \& Development Establishment, Armament \\ Post, Dr. Homi Bhabha Road, Pashan, Pune - 411021, India \\ ${ }^{2}$ Defence Institute of Advanced Technology, \\ Girinagar, Pune-411025, India \\ *E-mail: kddhote@gmail.com
}

\begin{abstract}
Understanding the dispersion characteristics of fragments is essential for precise planning of the end game and the neutralization of targets using directional fragment generator warheads (FGW). The authors have carried out experiments to study the spatial dispersion of the fragments in two configurations of FGWs having a circular shaped fragment generating surface. In this paper, the dispersion of the fragments is quantified using the mean and standard deviation of the projection angle. Using the Shapiro-Wilk test, it is verified that dispersion in the projection angle follows a normal distribution. The dispersion of the peripheral fragments is higher due to edge effects. A steeper variation in projection angles is observed for fragments placed at a radial distance greater than 0.7 times the explosive charge radius. These observations are in agreement with the results of Held (1988) for a square shaped fragment generating surface.
\end{abstract}

Keywords: fragment generator warhead, Taylor angle, fragment spatial dispersion, projection angle scatter, Shapiro-Wilk test

\section{Introduction}

Estimations of the fragment projection angle and velocity for conventional axisymmetric warheads have been studied by a number of researchers and their findings are reported in many publications spanning the last seven decades [1-14]. With the advancement in technology and demand for lighter effective armaments, 
efforts are being made to develop compact light weight warheads, one of these being the directional fragment generator warhead (FGW). Its configuration and spray pattern differ from the axi-symmetric conventional warhead as shown in Figure 1. In conventional warheads, the cylindrical metal casing breaks to form the fragments, whereas in FGWs, the fragments are generated by fragmentation of the metal disc at the end surface of the cylinder.

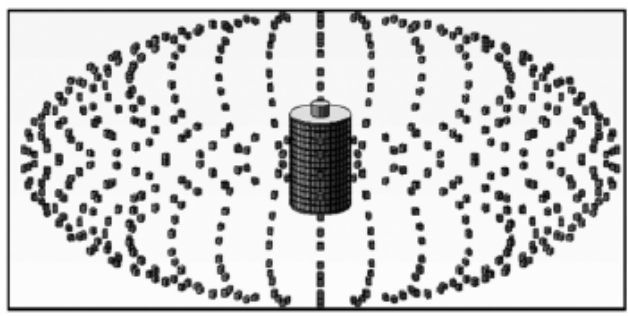

a) Axi-symmetric warhead

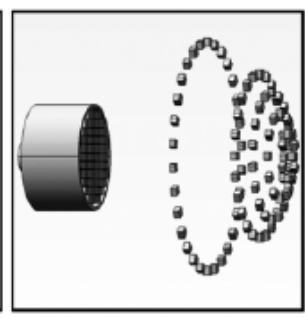

b) FGW

Figure 1. Fragment spatial distribution.

Gurney [1] derived algebraic equations for the velocity of metal in contact with detonating explosives for bombs, shells and grenades. The metal case velocity depends on the Gurney characteristic velocity and the ratio of the explosive charge mass (C) to the fragmenting metal case mass (M) [2]. Koch et al. [3] estimated the Gurney characteristic velocity, which is a characteristic of the explosive, to be around 1/3.08 times the detonation velocity. Furthermore, the derivation of the Gurney formula for spheres, cylinders, symmetric and asymmetric sandwich metal cases in contact with explosives, were given by Walters and Zukas [2]. The equations developed for cylinder and asymmetric sandwich metal cases are applicable for axi-symmetric warheads and FGWs, respectively. Lian et al. [4] observed that estimates for the asymmetric sandwich plate velocity using the equation overestimate the velocity for two dimensional configurations due to the neglect of lateral effects.

Early work on the estimation of the projection angle was done by Taylor [5], where he related the metal fragment velocity to the detonation velocity of the explosive. In his derivation, the fragment velocity was considered as uniform along the metal case and did not take into account the time period to attain it. Hence, the equation derived by Taylor gives lower values for the projection angles for short metal cases due to edge effects, where the energy transfer is unsteady. To overcome this shortcoming, Randers-Pehrson [6] considered the characteristic acceleration time for a metal casing with an assumed exponential function for the metal velocity. Furthermore, Chou et al. [7] have developed 
a generalized unsteady Taylor relation.

Many researchers have studied the fragment spray pattern of FGWs using experiments and simulations. Held [8] designed a fragment generator and determined the fragment hit density. He used flash X-ray photographs to determine the projection angle and velocity. Further work by Held [9] to launch a single fragment for a vulnerability study, revealed that sufficient aiming accuracy and consistent velocity of a fragment is possible in a single fragment generator. Lixin et al. [10] examined the design of a dense fragment generator to yield cumulative target damage by a concentrated fragment shower. From their results, it was observed that the peripheral fragments had wider projection angles and did not contribute to the cumulative effect on the target damage. Heavy confinement of the peripheral fragments reduces the dispersion of the metal fragments and hence enhances the target damage [11]. The end game dynamics, fragment delivery mechanisms, fragment impact obliquity considerations, fragment velocity and spray angle, probability of target inclusion and kill considerations have been discussed by Lloyd [12] for FGW designs.

Fragment spatial distribution is quantified by projection angles, which mainly depend on the ratio of explosive charge mass (C) to fragmenting disc metal mass (M), the ratio of charge length (L) to diameter (D), charge properties, charge initiation location, contour of fragmenting disc surface and FGW construction details. The typical range of $L / D$ is between 0.5 and 1.5 ; and the $\mathrm{C} / \mathrm{M}$ ratio varies between 0.5 and 3 . However, configurations beyond these ranges are also possible. Even in similar configurations of FGWs, variations in the projection angle was attributed to inherent deviations in the warhead, such as casing and explosive geometry, chemical and physical in-homogeneity in the explosive and the process of fragment laying on the disc. Furthermore, this was attributed to variations in the expansion and breaking of the fragmenting disc and casing, and the dynamics of the fragment acceleration process by explosion and fragment ballistics. The scatter in fragment projection angle for an axi-symmetric conventional fragmentation warhead was estimated using normal probability distribution with a standard deviation of $3^{\circ}[13]$.

Even though research on the fragment projection angle and velocity has been a subject of spirited scientific debate since 1940, there is still no systematic quantification on the statistical dispersion. The fragmentation warheads used in interceptor missile applications against ballistic missile targets need to be light-weight, compact, highly lethal and simple to operate. The relative velocity between the target ballistic missile and the interceptor missile is in the range of hypervelocities. As the relative velocity between the fragments and the target increases, precise information on fragment spatial location becomes more critical 
in planning end-game interception. The fragment mass and size need to be high in order to penetrate the multiple layers of the target and simultaneously they need to be large in number to cater for the uncertainty in target acquisition and cumulative damage by high hit density. The design of FGWs with wider dispersion characteristics leads to a heavier configuration and designs with narrower dispersion characteristics lead to underperforming FGWs. These contradictory requirements, along with the mass and space restrictions in the interceptor missile, call for trade-off studies in warhead configuration design.

The authors have carried out an experiment with a configuration having $\mathrm{C} / \mathrm{M}$ ratio of 1.0 with $\mathrm{L} / \mathrm{D}$ ratio of 0.8 to study the dispersion. The configuration was made with $6 \mathrm{~mm}$ Tungsten Alloy (TA) cubic fragments. In the experiment, each fragment's impact location on the target and its identification was used to map back to its original location for estimation of the projection angle. Statistical analysis of the trial data showed that the projection angle scatter follows a normal distribution. Subsequently, the authors carried out verification by conducting experiments with a configuration having $\mathrm{L} / \mathrm{D}$ of 0.5 with $\mathrm{C} / \mathrm{M}$ of 0.5 made of TA spherical fragments. Furthermore, a configuration having L/D of 1.5 and $\mathrm{C} / \mathrm{M}$ of 3.3 made of steel cubic fragments experimented by Held [8] is used for verification. These data confirmed that the scatter in the fragment projection angle follows a normal distribution. The standard deviation in the projection angles of the fragments in the radius of 0.7 times the explosive charge ranges are between $0.2^{\circ}$ and $1.4^{\circ}$.

\section{FGW Configurations}

\subsection{L/D of 0.8 and $C / M$ of 1.0}

The FGW configuration and fragment laying pattern is shown in Figure 2. The fragmenting disc consisted of $6 \mathrm{~mm}$ TA cubic fragments, which were laid on a $2 \mathrm{~mm}$ thick aluminum alloy disc using a resin mix, i.e. mixture of iron powder, resin and hardener. On top of the fragment surface, a $2 \mathrm{~mm}$ thick resin mix was built up, which was then covered by a $2 \mathrm{~mm}$ thick aluminum disc. This specific way of constructing the fragmenting disc aids in fragment spall mitigation [14] and helps to identify the fragment numbers on soft recovery. The fragments were identified by engraved numbers from 1 to 97 and arranged sequentially. The casing was made of $6 \mathrm{~mm}$ thick aluminum alloy and the explosive used was HMX/TNT (70/30). The size of the explosive column was $71 \mathrm{~mm}$ in diameter and $56 \mathrm{~mm}$ long. The booster was RDX/wax (95/5), $20 \mathrm{~mm}$ in diameter and $10 \mathrm{~mm}$ long. The warhead was initiated with an electrical detonator. 


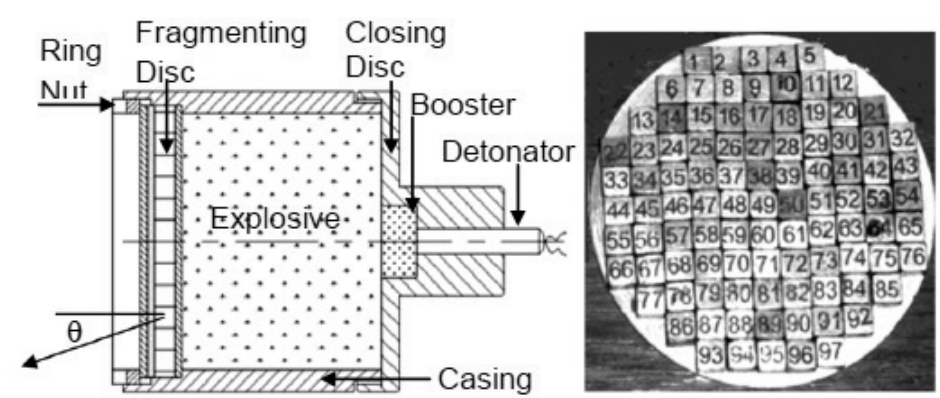

Figure 2. FGW having L/D of 0.8 and $\mathrm{C} / \mathrm{M}$ of 1.0 along with fragment laying pattern before application of resin mix.

The fragmenting disc was integrated into the casing by a ring nut, followed by an explosive casting. On curing the explosive, a closing disc along with a booster were threaded into the casing. Before firing, the warhead axis was aligned to the center of the target, and then a detonator was inserted in the hole provided in the closing disc. The fragment projection angle ' $\theta$ ' is shown in Figure 2.

\subsection{L/D of 0.5 and $\mathrm{C} / \mathrm{M}$ of 0.5}

The FGW configuration having L/D of 0.5 and $\mathrm{C} / \mathrm{M}$ of 0.5 is shown in Figure 3 . The fragmenting disc consisted of $9 \mathrm{~mm}$ diameter TA spherical fragments. The identification numbers were engraved on each fragment, from 1 to 37 . The size of the explosive column was $63 \mathrm{~mm}$ in diameter and $33 \mathrm{~mm}$ long. Other configuration details, explosive and initiation were the same as described in Section 2.1.
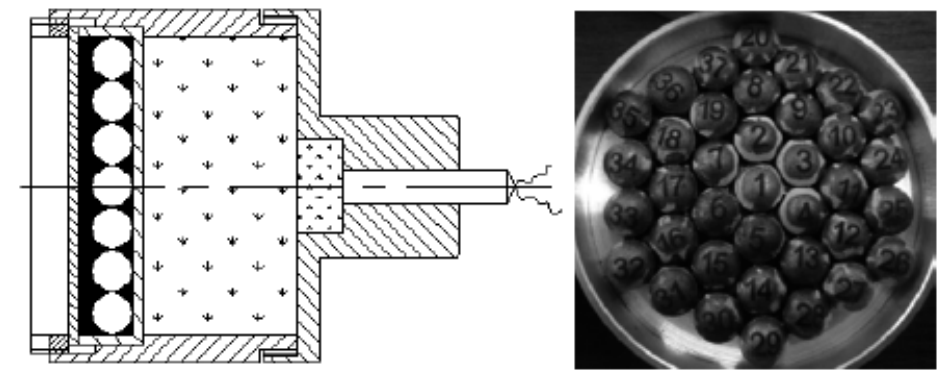

Figure 3. FGW having L/D of 0.5 and $\mathrm{C} / \mathrm{M}$ of 0.5 along with fragment laying pattern before application of resin mix. 


\section{Experimental Set-up}

A schematic diagram of the experimental set-up is shown in Figure 4. The target was made of wooden particle boards placed vertically against straw boards. It covered an area $2.4 \mathrm{~m}$ in height and $2.4 \mathrm{~m}$ in width. The warhead was kept at a distance of $5 \mathrm{~m}$ from the target. A V-block was placed on the wooden stand to position the warhead before firing. The warhead height was adjusted by a water level tube to the target center and the warhead axis was aligned to aim at the target center using a laser level meter. The fragment laying pattern was also aligned with the perpendicular axis of the target center line before firing. The FGW configurations described in Sections 2.1 and 2.2 were subjected to 9 and 2 trials, respectively. After each trial, the location of the fragment hole was marked and the fragment was recovered from the straw board stack. Knowing the fragment's impact co-ordinates on the target and its location in the fragmenting disc, the fragment projection angle was calculated.

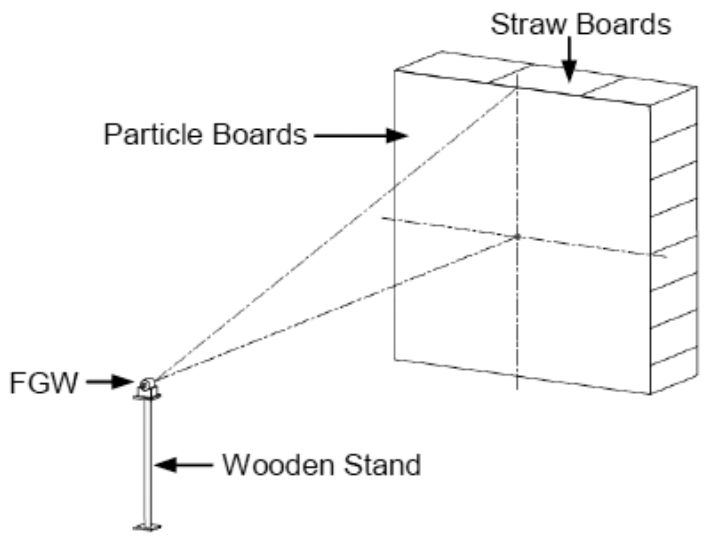

Figure 4. Schematic diagram of experimental set-up.

\section{Dispersion Analysis}

\subsection{FGW with $\mathrm{L} / \mathrm{D}$ of 0.8 and $\mathrm{C} / \mathrm{M}$ of 1.0}

Fragments having identical radial distances are expected to have similar projection angles due to axial symmetry and accordingly are grouped together for analysis. The groups from G1 to G13 were formed based on radial distance of the fragment centre from the FGW axis and are given in Table 1 . In a $90^{\circ}$ sector of the fragmenting disc, either one fragment or two fragments have identical radial 
distances due to the laying pattern followed in the fragmenting disc. The fragment laying pattern is shown in Figure 5. The radius ' $r$ ' represents the distance of the fragment centre from the warhead axis and ' $R$ ' represents the explosive charge radius, i.e. $35.5 \mathrm{~mm}$. Fragments on the periphery of the fragmenting disc, bearing numbers 1 to $6,12,13,21,22,32,33,43,44,54,55,65,66,76,77,85,86$ and 92 to 97 had large projection angles due to edge effects and barely $10 \%$ of them could be captured. Hence, they are not considered in the analysis. The radius of each group was estimated from the specific laying pattern, which is shown as an example for $\mathrm{G} 2$ and $\mathrm{G} 10$ in Figure 5 as $\mathrm{r}_{\mathrm{G} 2}$ and $\mathrm{r}_{\mathrm{G} 10}$, respectively.

Table 1. Groupwise dispersion: $\mathrm{L} / \mathrm{D}$ of 0.8 with $\mathrm{C} / \mathrm{M}$ of 1.0

\begin{tabular}{|l|l|l|l|l|l|c|}
\hline Group & \multicolumn{1}{|c|}{$\mathrm{r}^{\mathrm{a}}$} & \multicolumn{1}{c|}{$\mathrm{r}^{\mathrm{b}}$} & \multicolumn{1}{c|}{ Fragment No. $^{\mathrm{c}}$} & $\mu^{\mathrm{d}}$ & $\sigma^{\mathrm{e}}$ & $\mathrm{p}^{\mathrm{f}}$ \\
\hline G1 & 0 & 0 & 49 & 0.84 & 0.51 & 0.73 \\
\hline G2 & 6.2 & 0.17 & $38,48,50,60$ & 1.29 & 0.48 & 0.60 \\
\hline G3 & 8.8 & 0.25 & $37,39,59,61$ & 1.87 & 0.50 & 0.18 \\
\hline G4 & 12.4 & 0.35 & $27,47,51,71$ & 2.62 & 0.54 & 0.53 \\
\hline G5 & 13.9 & 0.39 & $26,28,36,40,58,62,70,72$ & 2.90 & 0.64 & 0.34 \\
\hline G6 & 17.5 & 0.49 & $25,29,69,73$ & 4.20 & 0.48 & 0.87 \\
\hline G7 & 18.6 & 0.52 & $17,46,52,81$ & 4.53 & 0.59 & 0.43 \\
\hline G8 & 19.6 & 0.55 & $16,18,35,41,57,63,80,82$ & 4.74 & 0.86 & 0.14 \\
\hline G9 & 22.4 & 0.63 & $15,19,24,30,68,74,79,83$ & 5.97 & 0.83 & 0.89 \\
\hline G10 & 24.8 & 0.70 & $9,45,53,89$ & 6.88 & 0.93 & 0.85 \\
\hline G11 & 25.6 & 0.72 & $8,10,34,42,56,64,88,90$ & 6.12 & 1.23 & 0.11 \\
\hline G12 & 26.3 & 0.74 & $14,20,78,84$ & 10.46 & 1.44 & 0.92 \\
\hline G13 & 27.7 & 0.78 & $7,11,23,31,67,75,87,91$ & 10.19 & 1.85 & 0.14 \\
\hline
\end{tabular}

${ }^{\mathrm{a}} \mathrm{r}$ is radius in $\mathrm{mm}$;

${ }^{\mathrm{b}} \mathrm{r} / \mathrm{R}$ is ratio of fragment group radial distance to explosive charge radius;

${ }^{\mathrm{c}}$ Fragment No. is the fragment identification number in the group;

${ }^{d} \mu$ is the mean projection angle in degrees;

${ }^{\mathrm{e}} \sigma$ is the standard deviation of the projection angle in degrees;

${ }^{\mathrm{f}} \mathrm{p}$ is $\mathrm{p}$-value of test statistics.

The group G1 (fragment No. 49) has a single datapoint of fragment projection angle in each trial. Other groups of 4 fragments and 8 fragments have 36 datapoints and 72 datapoints in 9 trials, respectively. The fragment projection angle scatter plots for groups G1, G3, G5, G7, G9, G11, G13 are shown in Figure 6. 


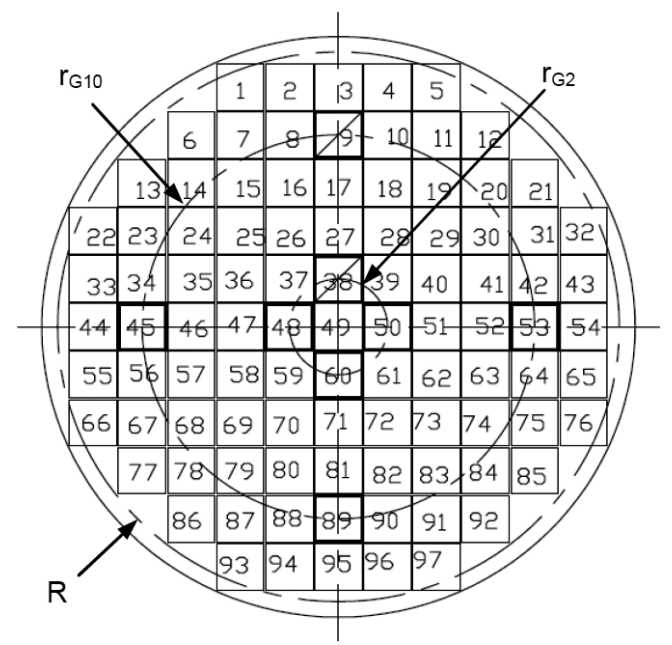

Figure 5. Fragment groups based on radial position.

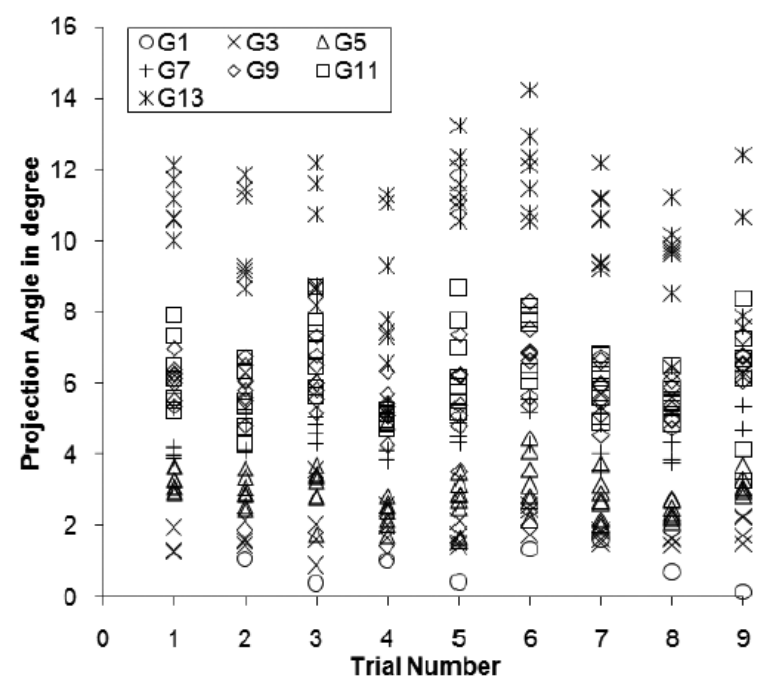

Figure 6. Scatter in projection angle for odd-numbered groups for L/D of 0.8 and $\mathrm{C} / \mathrm{M}$ of 1.0 .

The mean projection angle ' $\mu$ ' and standard deviation ' $\sigma$ ' in each group were calculated and are given in Table 1 . Their plot with reference to their radial position is shown in Figure 7. It was observed that the mean projection angle 
increases gradually with its radial position in the fragmenting disc up to $0.7 \mathrm{R}$, and beyond that it shows a steeper increase. Similarly, the observed standard deviation for the fragments occupying $0.52 \mathrm{R}$ area was around $0.5^{\circ}$, whereas fragments in the area of $0.55 \mathrm{R}$ to $0.7 \mathrm{R}$ has a standard deviation between $0.83^{\circ}$ and $0.93^{\circ}$. Beyond $0.7 \mathrm{R}$, the standard deviation also shows a steeper variation.

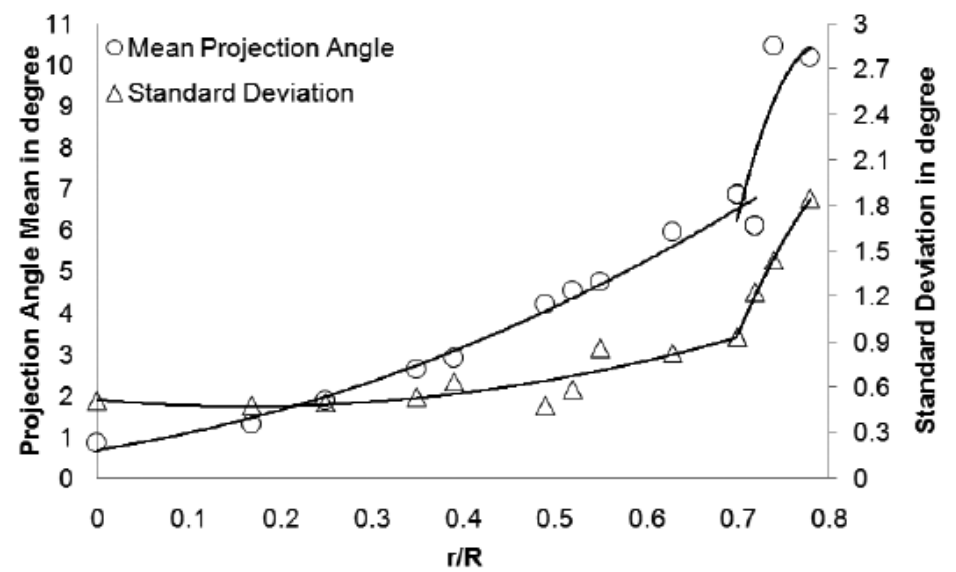

Figure 7. Variation of mean and standard deviation of projection angle with fragment radial position for a FGW with $\mathrm{L} / \mathrm{D}$ of 0.8 and $\mathrm{C} / \mathrm{M}$ of 1.0 .

The scatter in projection angle was hypothesized to follow a normal distribution and was verified by the Shapiro-Wilk test [15]. The projection angle data ' $x_{i}$ ' of each group was arranged in ascending order so that $x_{1} \leq \ldots \leq x_{n}$. The test statistic ' $W$ ' was estimated by Equation 1. The p-values of the test statistics are also given in Table 1. It was observed that the p-value was greater than the significance value of 0.05 . Hence, the null hypothesis of a normal distibution is retained. For the samples collected, the scatter in projection angle follows a normal distribution irrespective of its location in the fragmenting disc.

$$
W=\frac{b^{2}}{S S}
$$

where:

$$
\begin{aligned}
& b=\sum_{i=1}^{m} a_{i}\left(x_{n+1-i}-x_{i}\right) \\
& S S=\sum_{i=1}^{n}\left(x_{i}-\bar{x}\right)^{2}
\end{aligned}
$$




\subsection{FGW with $\mathrm{L} / \mathrm{D}$ of 0.5 and $\mathrm{C} / \mathrm{M}$ of 0.5}

Two trials with configurations having $\mathrm{L} / \mathrm{D}$ of 0.5 with $\mathrm{C} / \mathrm{M}$ of 0.5 were conducted. The projection angle data was compiled based on radial distance. Group 1 consisted of the central fragments. Other groups consisted of 6 fragments each. Thereby, 12 datapoints for each radial distance in two trials were recorded for groups 2 to 4 . The group details, their mean projection angle, standard deviation and p-value of test statistics are given in Table 2. The fragment scatter plot, along with the mean and standard deviation, is shown in Figure 8 . The peripheral fragments bearing numbers 20 to 37 have $\mathrm{r} / \mathrm{R}$ ratios 0.76 and 0.86 , respectively. They had projection angles greater than $13.5^{\circ}$ and hence could not be captured.

In this case too, the mean projection angle and standard deviation increases gradually until $0.57 \mathrm{R}$ and the $\mathrm{p}$-value is greater than 0.05 . Hence, the hypothesis of a normal distribution can be retained.

Table 2. Group wise dispersion: $\mathrm{L} / \mathrm{D}$ of 0.5 with $\mathrm{C} / \mathrm{M}$ of 0.5

\begin{tabular}{|l|l|l|l|l|l|c|}
\hline Group & \multicolumn{1}{|c|}{$\mathrm{r}^{\mathrm{a}}$} & \multicolumn{1}{c|}{$\mathrm{r} / \mathrm{R}^{\mathrm{b}}$} & \multicolumn{1}{|c|}{ Fragment No. ${ }^{\mathrm{c}}$} & $\mu^{\mathrm{d}}$ & $\sigma^{\mathrm{e}}$ & $\mathrm{p}^{\mathrm{f}}$ \\
\hline G1 & 0 & 0 & 1 & 0.73 & 0.32 & - \\
\hline G2 & 9.0 & 0.29 & $2,3,4,5,6,7$ & 4.54 & 0.87 & 0.45 \\
\hline G3 & 15.5 & 0.49 & $9,11,13,15,17,19$ & 7.90 & 0.93 & 0.36 \\
\hline G4 & 18.0 & 0.57 & $8,10,12,14,16,18$ & 9.02 & 1.43 & 0.09 \\
\hline
\end{tabular}

a, b, c, d, e, f, descriptions like under Table 1 .

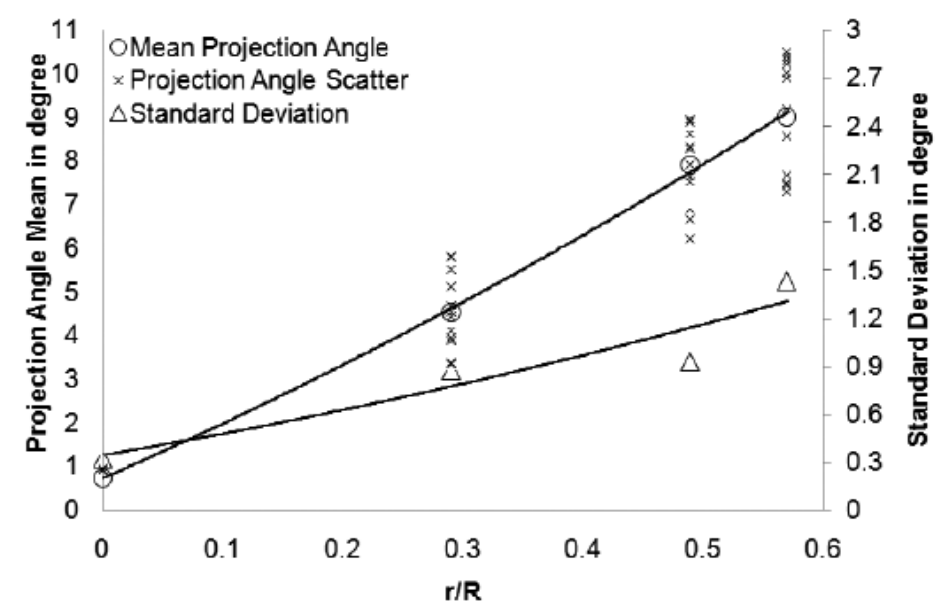

Figure 8. Variation of mean and standard deviation of projection angle with fragment radial position for a FGW with $\mathrm{L} / \mathrm{D}$ of 0.5 and $\mathrm{C} / \mathrm{M}$ of 0.5 . 


\subsection{FGW with $L / D$ of 1.5 and $C / M$ of 3.3}

The FGW experiment performed by Held [8] used a square-shaped fragment generating surface. A total of 81 cubic fragments were arranged in 9 rows $(a$ to $i)$ and 9 columns ( 1 to 9 ). From the geometry and projection angle data $(\alpha, \xi)$ given in reference [8], each fragment projection angle was calculated and is given in Table 3. The explosive used was $\mathrm{C} 4$ and was hand filled in the steel casing. Its density was considered to be $1.65 \mathrm{~g} / \mathrm{cm}^{3}(\mathrm{C}=930 \mathrm{~g})$ with a fragment mass (M) of $284 \mathrm{~g}$. Hence, the configuration has $\mathrm{C} / \mathrm{M}$ ratio of 3.3. In order to compare the results from the square-shaped $(70 \mathrm{~mm} \times 70 \mathrm{~mm})$ fragment laying area [8] with the circular shaped fragmenting disc of the current FGW experiments, the square area was converted to an equivalent circular area. The equivalent case radius was taken to be $39.5 \mathrm{~mm}$ (i.e. the square root of $70^{2} / \pi$ ). Hence, $\mathrm{L} / \mathrm{D}$ of the configuration was 1.5. Due to this convention, $\mathrm{r} / \mathrm{R}$ ratio for the corner fragments was greater than 1 .

Table 3. Projection angle in degrees for $\mathrm{L} / \mathrm{D}$ of 1.5 with $\mathrm{C} / \mathrm{M}$ of 3.3

\begin{tabular}{|c|c|c|c|c|c|c|c|c|c|}
\hline $\begin{array}{c}\text { Frag. } \\
\text { ID }^{\mathbf{a}}\end{array}$ & 1 & 2 & 3 & 4 & 5 & 6 & 7 & 8 & 9 \\
\hline $\mathbf{a}$ & 16.9 & 14.5 & 12.7 & 11.1 & 10.9 & 10.9 & 12.0 & 13.3 & 16.5 \\
\hline $\mathbf{b}$ & 13.2 & 9.3 & 8.0 & 6.2 & 6.1 & 6.6 & 8.1 & 8.7 & 13.3 \\
\hline $\mathbf{c}$ & 12.1 & 7.9 & 6.4 & 5.4 & 4.5 & 5.3 & 5.8 & 6.9 & 12.0 \\
\hline $\mathbf{d}$ & 11.1 & 7.4 & 5.0 & 3.8 & 2.7 & 3.5 & 4.9 & 5.6 & 10.6 \\
\hline $\mathbf{e}$ & 11.3 & 6.2 & 4.2 & 3.3 & 0.5 & 2.5 & 5.1 & 5.3 & 10.2 \\
\hline $\mathbf{f}$ & 11.5 & 6.4 & 5.8 & 3.9 & 2.7 & 3.6 & 4.5 & 6.0 & 11.0 \\
\hline $\mathbf{g}$ & 12.3 & 7.3 & 5.9 & 5.5 & 5.1 & 4.8 & 7.0 & 7.5 & 11.7 \\
\hline $\mathbf{h}$ & 13.6 & 9.9 & 7.6 & 6.1 & 5.4 & 6.1 & 7.2 & 9.3 & 13.7 \\
\hline $\mathbf{i}$ & 17.5 & 14.4 & 11.8 & 11.1 & 10.4 & 11.2 & 12.4 & 13.3 & 15.6 \\
\hline
\end{tabular}

${ }^{a}$ Frag. ID means fragment identification.

For scatter analysis, fragments with the same ratio of radial distance to equivalent radius were grouped and are given in Table 4. A projection angle scatter plot, along with mean and standard deviation, is shown in Figure 9. It was observed that the mean projection angle increases up to $\mathrm{r} / \mathrm{R} 0.71$ and thereafter increases at a steeper rate. However, the standard deviation has values between $0.18^{\circ}$ and $0.78^{\circ}$ with the maximum for G15. The p-value for the test statistics was greater than 0.05 except for G14. 
Table 4. Groupwise dispersion: $\mathrm{L} / \mathrm{D}$ of 1.5 with $\mathrm{C} / \mathrm{M}$ of 3.3

\begin{tabular}{|l|l|l|l|l|l|c|}
\hline Group & \multicolumn{1}{|c|}{$\mathrm{r}^{\mathrm{a}}$} & \multicolumn{1}{c|}{$\mathrm{r} / \mathrm{R}^{\mathrm{b}}$} & \multicolumn{1}{c|}{ Fragment No. $^{\mathrm{c}}$} & \multicolumn{1}{c|}{$\mu^{\mathrm{d}}$} & \multicolumn{1}{c|}{$\sigma^{\mathrm{e}}$} & $\mathrm{p}^{\mathrm{f}}$ \\
\hline G1 & 0 & 0 & $\mathrm{e} 5$ & 0.49 & - & - \\
\hline G2 & 7.8 & 0.20 & $\mathrm{~d} 5, \mathrm{e} 6, \mathrm{f} 5, \mathrm{e} 4$ & 2.81 & 0.36 & 0.29 \\
\hline G3 & 11.0 & 0.28 & $\mathrm{~d} 4, \mathrm{~d} 6, \mathrm{f} 4, \mathrm{f} 6$ & 3.67 & 0.18 & 0.49 \\
\hline G4 & 16.5 & 0.42 & $\mathrm{c} 5, \mathrm{e} 7, \mathrm{~g} 5, \mathrm{e} 3$ & 4.70 & 0.43 & 0.23 \\
\hline G5 & 17.4 & 0.44 & $\mathrm{c} 4, \mathrm{c} 6, \mathrm{~d} 7, \mathrm{f} 7, \mathrm{~g} 6, \mathrm{~g} 4, \mathrm{f} 3, \mathrm{~d} 3$ & 5.14 & 0.45 & 0.77 \\
\hline G6 & 22.1 & 0.56 & $\mathrm{c} 3, \mathrm{c} 7, \mathrm{~g} 7, \mathrm{~g} 3$ & 6.30 & 0.55 & 0.44 \\
\hline G7 & 23.4 & 0.59 & $\mathrm{~b} 5, \mathrm{e} 8, \mathrm{~h} 5, \mathrm{e} 2$ & 5.76 & 0.49 & 0.15 \\
\hline G8 & 24.7 & 0.62 & $\mathrm{~b} 4, \mathrm{~b} 6, \mathrm{~d} 8, \mathrm{f} 8, \mathrm{~h} 6, \mathrm{~h} 4, \mathrm{f} 2, \mathrm{~d} 2$ & 6.30 & 0.54 & 0.51 \\
\hline G9 & 28.1 & 0.71 & $\mathrm{b3}, \mathrm{b} 7, \mathrm{c} 8, \mathrm{~g} 8, \mathrm{~h} 7, \mathrm{~h} 3, \mathrm{~g} 2, \mathrm{c} 2$ & 7.57 & 0.42 & 0.69 \\
\hline G10 & 31.2 & 0.79 & $\mathrm{a} 5, \mathrm{e} 9, \mathrm{i} 5, \mathrm{e} 1$ & 10.7 & 0.50 & 0.72 \\
\hline G11 & 32.2 & 0.81 & $\mathrm{a} 4, \mathrm{a}, \mathrm{d} 9, \mathrm{f} 9, \mathrm{i} 6, \mathrm{i} 4, \mathrm{~d} 1, \mathrm{f1}$ & 11.07 & 0.25 & 0.62 \\
\hline G12 & 33.1 & 0.84 & $\mathrm{~b} 2, \mathrm{~b} 8, \mathrm{~h} 8, \mathrm{~h} 2$ & 9.32 & 0.47 & 0.73 \\
\hline G13 & 34.9 & 0.88 & $\mathrm{a} 3, \mathrm{a} 7, \mathrm{c} 9, \mathrm{~g} 9, \mathrm{i} 7, \mathrm{i} 3, \mathrm{~g} 1, \mathrm{c} 1$ & 12.14 & 0.33 & 0.75 \\
\hline G14 & 39.0 & 0.99 & $\mathrm{a} 2, \mathrm{a} 8, \mathrm{~b} 9, \mathrm{~h} 9, \mathrm{i} 8, \mathrm{i} 2, \mathrm{~h} 1, \mathrm{~b} 1$ & 13.67 & 0.51 & 0.02 \\
\hline G15 & 44.1 & 1.12 & $\mathrm{a} 1, \mathrm{a} 9, \mathrm{i} 9, \mathrm{i} 1$ & 16.64 & 0.78 & 0.88 \\
\hline
\end{tabular}

a, b, c, d, e, f, descriptions like under Table 1 .

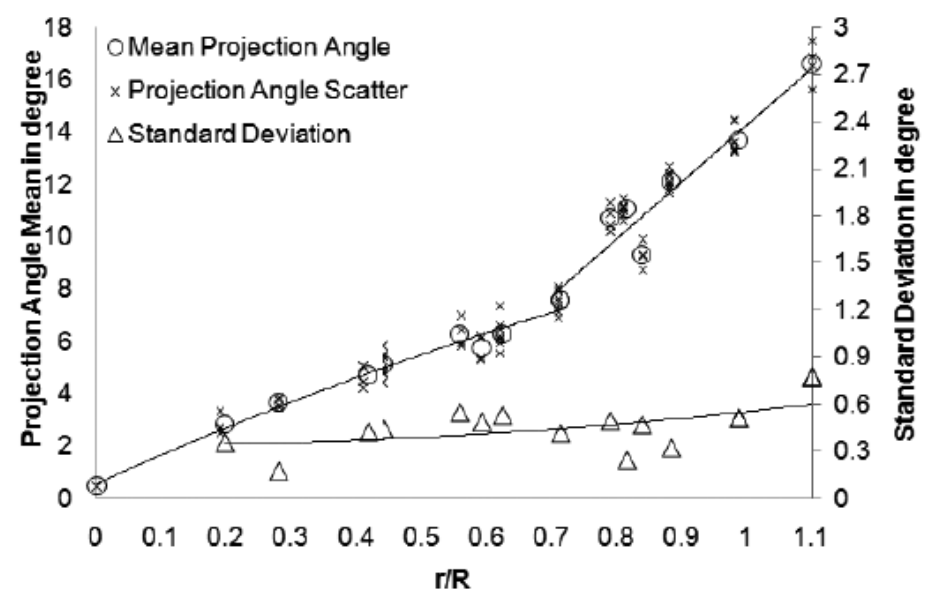

Figure 9. Variation of mean and standard deviation of projection angle with fragment radial position for a FGW with $\mathrm{L} / \mathrm{D}$ of 1.5 and $\mathrm{C} / \mathrm{M}$ of 3.3. 


\section{Discussion}

From the analysis of the experimental data of the three configurations of FGWs, it was observed that the projection angle increases with its radial location in the fragmenting surface. The detonation wave front in the explosive, first interacts with the central fragment in the fragmenting disc. Then, the interaction front progresses towards the peripheral fragments. By virtue of the shape of the detonation wave front, as the radial distance increases, more radial momentum is imparted to the fragments [16].

The effect of the $\mathrm{L} / \mathrm{D}$ ratio on the projection angle can also be observed from the experimental results. As the explosive column length increases, the detonation wave front at fragmenting surface becomes flatter, resulting in less radial momentum being transfered to the fragments, which reduces the projection angle. Hence, the dispersion is higher for the FGW having $\mathrm{L} / \mathrm{D}$ of 0.5 with $\mathrm{C} / \mathrm{M}$ of 0.5 compared to the other two configurations. A straight line fit for the projection angle having $\mathrm{r} / \mathrm{R}$ less than 0.7 gives a slope of $14.67^{\circ}$ for the configuration having $\mathrm{L} / \mathrm{D}$ of 0.5 with $\mathrm{C} / \mathrm{M}$ of 0.5 . For the other two configurations, the slopes were $8.81^{\circ}$ (L/D of 0.8 with $\mathrm{C} / \mathrm{M}$ of 1.0 ) and $9.27^{\circ}$ (L/D of 1.5 with $\mathrm{C} / \mathrm{M}$ of 3.3 ), respectively.

The projection angle increases at a steeper rate for fragments located beyond $0.7 \mathrm{R}$ due to edge effects. In the case of finite peripheral boundaries, as in the FGW, rarefaction waves are generated from the edges of the explosive after propagation of the detonation wave. As explained by Held [17], pressure builds up more in the direction of propagation than in the radial direction. Furthermore, the periphery pressure in the detonation flow process becomes reduced due to rarefaction, resulting in lower reaction rates and velocity of detonation. Hence, the shape of the detonation wave front becomes steeper close to the explosive cylindrical surface. Therefore, the wave front interaction with the peripheral fragment disc surface is of lower intensity than the central region $(<0.7 \mathrm{R})$, resulting in lower axial and higher radial momentum for the peripheral fragments.

\section{Conclusions}

The authors have performed an experimental study to characterize fragment dispersion in FGWs having L/D of 0.8 with $\mathrm{C} / \mathrm{M}$ of 1.0 , and $\mathrm{L} / \mathrm{D}$ of 0.5 with $\mathrm{C} / \mathrm{M}$ of 0.5. Published dispersion data for $\mathrm{L} / \mathrm{D}$ of 1.5 with $\mathrm{C} / \mathrm{M}$ of 3.3 configuration were also analyzed. The p-values from the Shapiro-Wilk test confirmed that the statistical approach can be used to quantify the fragment dispersion from 
FGWs. It was observed that the projection angles vary gradually with reference to fragment position in the fragmenting disc up to 0.7 times the explosive charge radius $(\mathrm{R}=35.5 \mathrm{~mm})$, and beyond this range edge effects were predominant, leading to higher projection angles $\left(>8^{\circ}\right)$ for the configurations studied. The dispersion in projection angle followed a normal distribution for fragments from the central core $(r<0.7 \mathrm{R})$, with a standard deviation less than $1.43^{\circ}$. Furthermore, it was concluded that lower L/D configurations result in higher projection angles and standard deviations compared to higher L/D configurations. Also, the projection angle increases at a steeper rate of $14.67^{\circ}$ for a lower $\mathrm{L} / \mathrm{D}$ of 0.5 , as compared to $8.81^{\circ}$ and $9.27^{\circ}$ for configurations with $\mathrm{L} / \mathrm{Ds}$ of 0.8 and 1.5 , respectively.

\section{References}

[1] Gurney R.W., The Initial Velocities of Fragments from Bombs, Shells and Grenades, BRL Report No. 405, Aberdeen Proving Ground, Maryland, USA, 1943.

[2] Walters W.P., Zukas J.A., The Gurney Velocity Approximation, in: Fundamentals of Shaped Charges, John Wiley \& Sons, New York, USA, 1989, pp. 45-71, ISBN 9780471621720.

[3] Koch A., A Simple Relation between the Detonation Velocity of an Explosive and its Gurney Energy, Propellants Explos. Pyrotech., 2002, 27, 365-368.

[4] Lian Y.P., Zhang X., Zhou X., Ma S., Zhao Y.L., Numerical Simulation of Explosively Driven Metal by Material Point Method, Int. J. Impact Eng., 2011, $38,238-246$.

[5] Taylor G.I., Analysis of the Explosion of a Long Cylindrical Bomb Detonated at One End, in: The Scientific Papers of G. I. Taylor, Vol. 111, Cambridge University Press, UK, 1963, pp. 277-286.

[6] Randers-Pehrson G., An Improved Equation for Calculating Fragment Projection Angles, Proc. $2^{\text {nd }}$ Int. Symp. on Ballistics, Daytona Beach, FL, USA, 1977.

[7] Chou P.C., Carleone J., Flis W.J., Ciccarelli R.D., Hirsch E., Improved Formulas for Velocity, Acceleration and Projection Angle of Explosively Driven Liners, Propellants Explos. Pyrotech., 1983, 8,175-183.

[8] Held M., Fragment Generator, Propellants Explos. Pyrotech., 1988, 13, 135-143.

[9] Held M., Single Fragment Generator, Propellants Explos. Pyrotech., 2000, 25, $8-12$.

[10] Lixin Q., Ming Q., Yu W., Yongqing Z., Daojian J., Dense Fragment Generator, Propellants Explos. Pyrotech., 2002, 27, 267-278.

[11] Zlatkis A., Korin N., Gofman E., Edge Effects on Fragments Dispersion, Proc. $23^{\text {rd }}$ Int. Symp. on Ballistics, Tarragona, Spain, 2007.

[12] Lloyd R.M., Forward Firing Warhead Technology, in: Physics of Direct Hit and 
Near Miss Warhead Technologies, (Zarchan P., Ed.), Progress in Astronautics \& Aeronautics, Vol. 194, American Institute of Aeronautics and Astronautics, USA, 2001, p. 199.

[13] AMC Pamphlet. Research and Development of Material: Engineering Design Handbook Warheads-General (U), AMCP 706-290, Headquarters, United States Army Material Command, Washington, D.C., USA, 1964, p. 51.

[14] Dhote K.D., Verma P.N., Murthy K.P.S., Mitigation of Fragment Spall Induced by Explosive Loading in High Performance Fragment Generators, Journal of Battlefield Technology, 2014, 17(1), 6-8.

[15] Shapiro S.S., Wilk M.B., An Analysis of Variance Test for Normality, Biometrika, 1965, 52(3/4), 591-611.

[16] Dhote K.D., Murthy K.P.S., Rajan K.M., Sucheendran M.M., Dynamics of Multi Layered Fragment Separation by Explosion, Int. J. Impact Eng., 2015, 75, 194-202.

[17] Held M., Corner-turning Distance and Retonation Radius, Propellants Explos. Pyrotech., 1989, 14, 153-161. 
